Military Technical College

Kobry Elkobbah,

Cairo, Egypt

April 3-5,2018

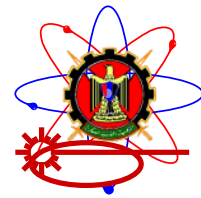

9th International Conference

on Mathematics and

Engineering Physics (ICMEP-9)

\title{
Hyper-Spectral Laser Imaging of Under-Water Targets
}

\author{
M. Darwiesh ${ }^{1}$, Ashraf F. El-Sherif ${ }^{2}$, HS Ayoub ${ }^{3}$, Yasser H. El-sharkawy ${ }^{4}$, and \\ Mahmoud F. Hassan ${ }^{5}$ \\ 1,2,5 Engineering Physics Department, Military Technical College, Cairo, Egypt. \\ ${ }^{4}$ Biomedical Engineering Department, Military Technical College, Cairo, Egypt. \\ ${ }^{3}$ Physics Department, Cairo University, Cairo, Egypt. \\ e-mail: M.darweesh@mtc.edu.eg
}

In this work an exclusive hyper spectral imaging system was implemented to detect immerged and sub-immerged targets in aqua environments using laser illumination. Under different water extinction levels, the system was capable of detecting and differentiating between several dummy targets with different colors and shapes. A study of the effect of deep background on the target identification is also inclusive. The tests revealed a strong dependence of target detectivity on the laser wavelength, the water turbidity and target surface shape and color. This work helps in the future design of air-born under water target detection system capable of tracking stealth submarine at different depths and aqua environments.

\section{Introduction:}

Challenges associated with obtaining visibility of objects at long or short distances have been difficult to overcome due to the absorptive and scattering nature of seawater. Mitigating these effects has been the focus of the underwater imaging community for decades, the main problem is the complicated optical environment such as intrinsic absorption by water, dissolved impurities, organic matter and scattering from the water, impurities including organic and inorganic particulate, which limits both the working distance and the resolution of underwater optical system $[1,2]$. Especially, the scattering of water and particulate, generating grave light noise and blurring the figure line of target, directly influence image quality and resolution. Fig.1 shows the light absorption and scattering in pure water. Chen YangWei, HuaZhong Institute of photoelectric technology, Wu Han, China, has researched the attenuation underwater of different wavelength laser in natural water, and given the variety of wavelength laser's attenuation in different turbidity condition (fig 2.) [3]. From these two figures, we can find that the blue-green light can be less attenuated in water, so majority of underwater optical system regard blue-green light, especially laser light due to more intense energy density and stronger in anti-interference as illumination resource or transmitter. 
Military Technical College

Kobry Elkobbah,

Cairo, Egypt

April 3-5,2018

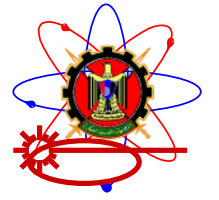

9th International Conference on Mathematics and Engineering Physics (ICMEP-9)

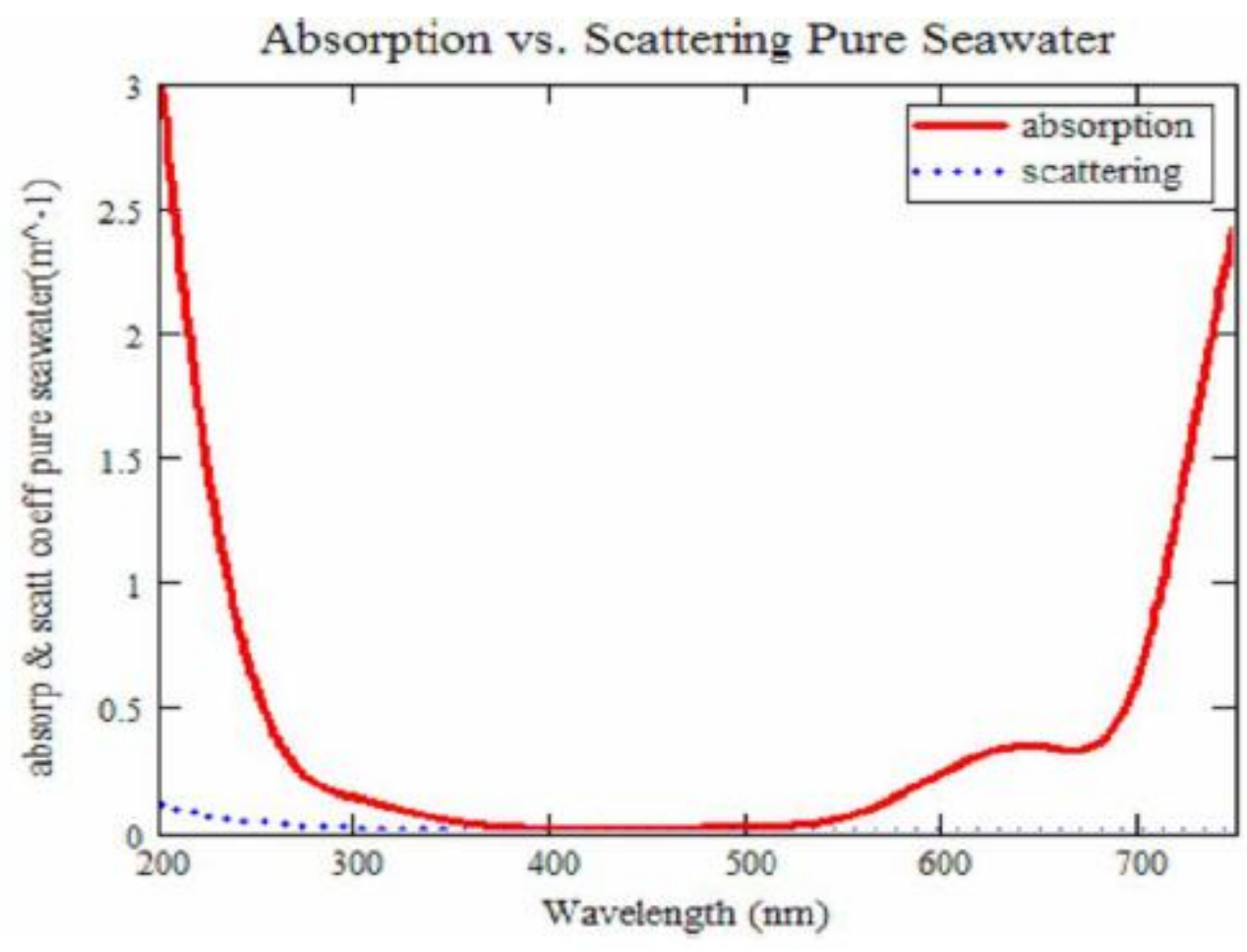

Fig.1 Absorption vs. Scattering Pure Seawater

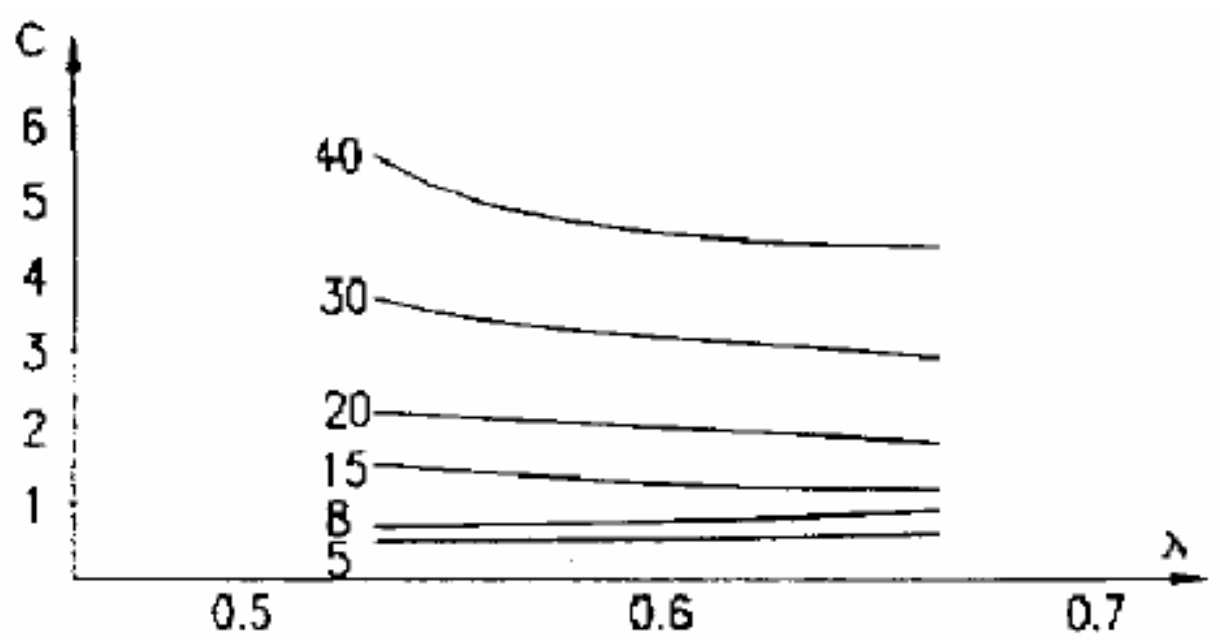

Fig. 2 Attenuation relationship of wavelength and turbidity 
Military Technical College

Kobry Elkobbah,

Cairo, Egypt

April 3-5,2018

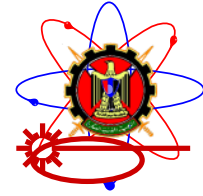

9th International Conference on Mathematics and

Engineering Physics (ICMEP-9)

One of the biggest challenges in detecting underwater objects in hyperspectral imaging because the observed spectrum is highly dependent on the optical properties of the surrounding environment (background - water turbidity - laser wavelength - target camouflage and depth - target detection angle) which strongly affects the target detectivity

\section{Theory:}

\subsection{Optical properties of water:}

As light propagates through water, light is absorbed and scattered in the water column. UV and IRlight are heavily attenuated in water. In clear ocean water, the deepest penetrating light is in the blue part of the spectrum with a maximum 1\% light depth of $\sim 300 \mathrm{~m}$, which is the depth where the light energy is $1 \%$ of the energy at the surface as shown in fig. 3 in the demonstrating diagram. Compared with fjord waters, where the color is in the green part, maximum 1\% light depth is $\sim 50$ $\mathrm{m}[4,5]$.

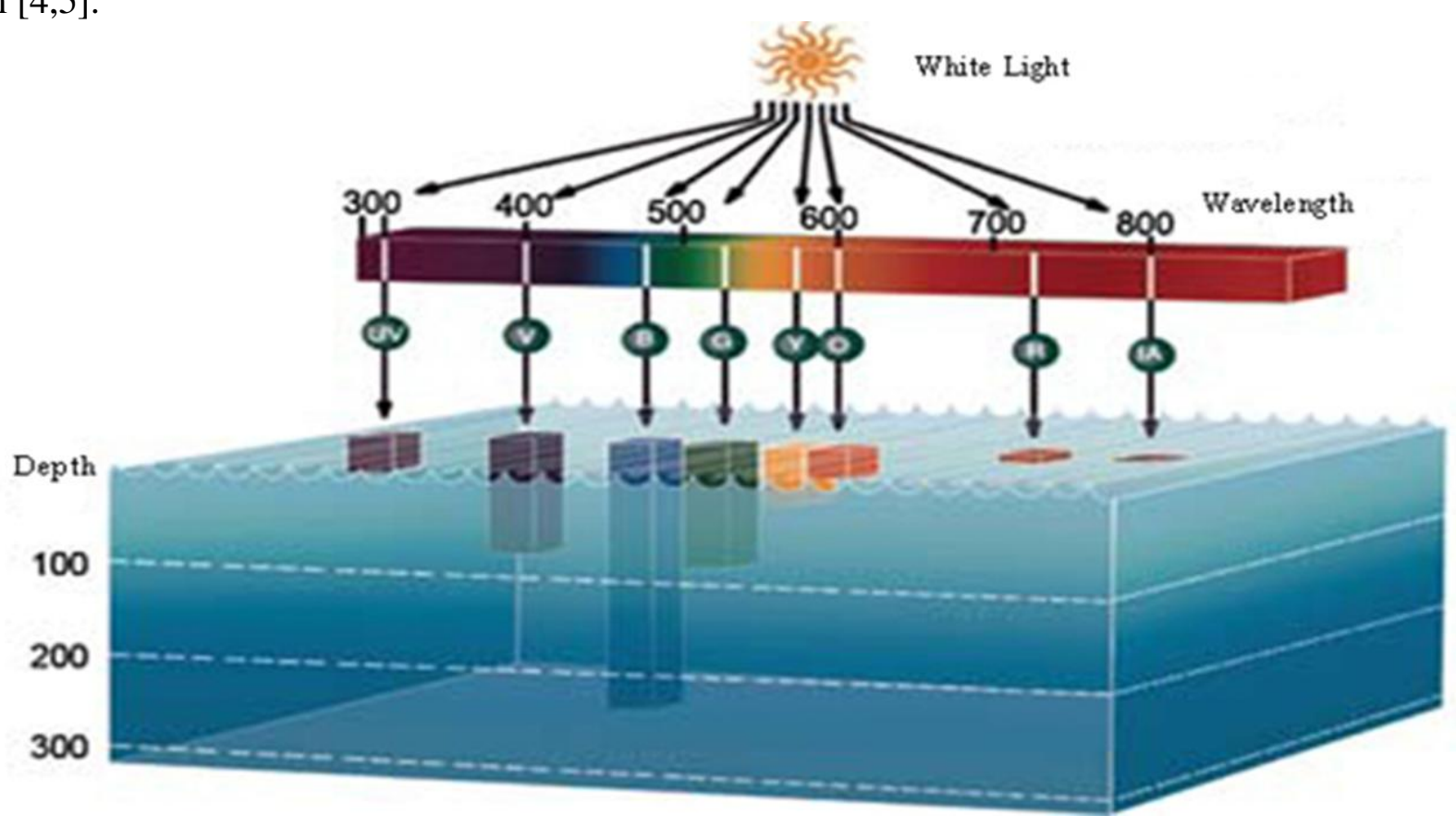

Fig.3 the depth that light penetrates in clear ocean water.

\subsection{Optical Significant Constituents of Natural Waters}

In order to estimate the correct values of the absorbing and scattering coefficient of natural waters, we need to have some knowledge of the composition of those waters. Natural waters contain a continuous size distribution of particles ranging from water molecules of size $0.1 \mathrm{~nm}$, to small organic molecules of size $1 \mathrm{~nm}$, to large organic molecules of size $10 \mathrm{~nm}$, to viruses of size $100 \mathrm{~nm}$, to ..., to whales of size $10 \mathrm{~m}$, to submarines of size $100 \mathrm{~m}$. Strictly speaking, natural waters are 


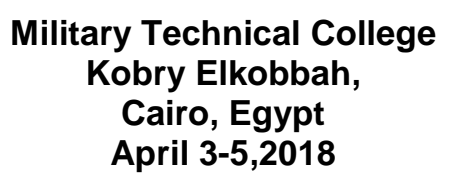

Military Technical College

obry Elkobbah,

April 3-5,2018

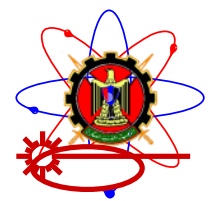

composed of particles. Traditionally the constituents of natural waters are divided into "dissolved" and "particulate" matters, of organic and inorganic origins, living and nonliving.

Pure sea water consists of pure water plus various dissolved salts, which average about 35 parts per thousand $(35 \%)$ by weight. These salts increase scattering, and make the scattering from pure sea water $30 \%$ bigger than the scattering from pure water. These salts have a negligible effect on absorption at visible wavelengths, so in our case the salt is not going to be one of the limiting factor, but it is likely that they increase absorption somewhat at ultraviolet wavelengths and the increase is bigger while the wavelength is extremely long.

Dissolved organic compounds are produced during the decay of plant matter and consist mostly of various humic and fulvic acids [6].Generally are brown and in sufficient concentrations they colour the water yellowish brown, so they are called yellow matter or colored dissolved organic matter. They have to be taken in care at blue and ultraviolet wavelengths because the absorption increases. In ocean waters, the absorption by yellow matter is usually small compared to absorption by other constituents like phytoplankton.

Particulate matter has two different origins: biological or physical. The organic particles of optical importance are created as bacteria, phytoplankton, and zooplankton grow and reproduce. Inorganic particles are created primarily by weathering of terrestrial rocks and soils. These particles can enter the water as wind-blown dust settles on the sea surface, or as rivers carry eroded soil to the sea. This particulate matter usually is the major determiner of absorption and scattering properties of natural waters.

Phytoplankton are These ubiquitous microscopic plants occur with incredible diversity of species, size, shape, and concentration. Phytoplankton are the particles primarily responsible for determining the optical properties of most oceanic waters. Their chlorophyll and related pigments absorb light in the blue and red and thus, when concentrations are high, predominate in determining the spectral absorption of sea water. These particles are generally much larger than the wavelength of visible light and are efficient scatterers, especially via diffraction, thus strongly influencing the total scattering properties of sea water.

Inorganic particles generally consist of finely ground quartz sand, clay minerals, or metal oxides in the size range from much less than $1 \mu \mathrm{m}$ to several tens of micrometers. Sometimes inorganic particles are optically more important than organic particles, but the attentions that have been made to them have been insufficient. Such situations can occur both in turbid coastal waters carrying a heavy sediment load and in very clear oceanic waters that are receiving windblown dust [6].

The phytoplankton coccolithophore species is a most remarkable biological source of crystalline particles. During blooms they produces and sheds enormous numbers of small calcite plates that have a negligible effect on light absorption but are extremely efficient light scatterers: they have a irradiance reflectances of $R=0.39$ at blue wavelengths during blooms (compared with $R=0.02$ to 0.05 in the blue for typical ocean waters). Such coccolithophore blooms give the ocean a milky white or turquoise appearance.

\subsection{Underwater Fluorescence:}


Military Technical College

Kobry Elkobbah,

Cairo, Egypt

April 3-5,2018

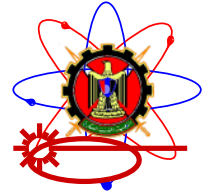

9th International Conference on Mathematics and

Engineering Physics (ICMEP-9)

Fluorescence is the phenomenon by which light (electromagnetic radiation) is absorbed at one wavelength and re-emitted at another, longer wavelength. Many marine organisms contain fluorescent substances, and the right excitation light source can reveal surprising new colors and patterns. While there were sporadic early scientific investigations of instances of fluorescence in the marine environment, more focused research projects are of very recent vintage. Despite this, fluorescence is already proving to be a useful tool for a variety of marine science applications [7]. The emission spectrum is the distribution of light energy as a function of wavelength for the emitted light, while the excitation spectrum is a graph of the relative ability of different wavelengths of light to stimulate, or excite, the fluorescence. Fig. 4A shows the emission spectra for two of the fluorescent proteins commonly found in corals. We often describe spectra such as these by their peak (the wavelength of maximum energy) and their width, defined as the full width at half maximum intensity (abbreviated as FWHM). We can see that the cyan-fluorescing protein with the peak at $486 \mathrm{~nm}$ has a much broader emission than the green-fluorescing protein with a peak at $515 \mathrm{~nm}$. Emission spectra can be diagnostic or at least strongly indicative of the identity of a fluorescing molecule, and can therefore be a tool for interpreting fluorescence responses. For example, chlorophyll has a characteristic fluorescence emission in the deep red, with a peak at approximately $685 \mathrm{~nm}$. So far nothing else has been noted in the marine environment with a similar emission [8].

Fig. 4B shows the excitation spectra for the two proteins for which the emission spectra are shown in Fig. 4A. This graph tells you several useful things. The 'best' wavelength of light to excite the cyan protein is at about $440-450 \mathrm{~nm}$, while the 'best' wavelength to excite the green protein is at about $500 \mathrm{~nm}$. Neither of these 'best' wavelengths for either pigment is very good for exciting the other. And these are just two of the many fluorescing pigments found in nature.
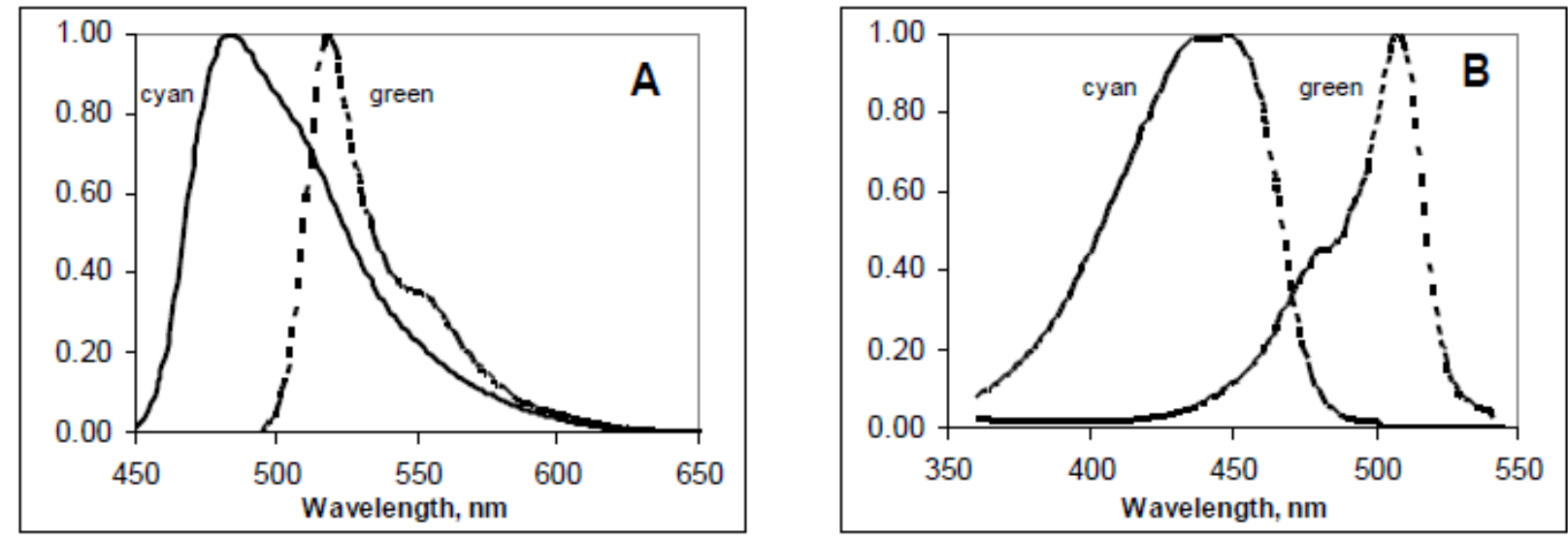

Fig.4. Emission (A) and excitation (B) spectra for two of the common fluorescent pigments found in corals.

This tells us that there is no single ideal wavelength for stimulating all fluorescence, and we have to make some intelligent compromises in choice of a light source. In practice we have found that a source with broad emission in the blue (wavelengths shorter than about $460 \mathrm{~nm}$ ) is an effective option. 
Military Technical College

Kobry Elkobbah,

Cairo, Egypt

April 3-5,2018

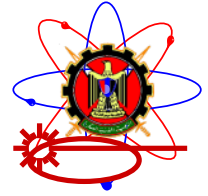

9th International Conference on Mathematics and

Engineering Physics (ICMEP-9)

The excitation spectrum tells you what the best wavelength is to excite any given pigment, but it doesn't tell you how intensely the pigment will glow. What is important for that is the fluorescence efficiency, defined as the photons of light emitted divided by the photons of light absorbed. Many substances absorb light, but not all fluoresce, and among those that do, some fluoresce more brightly than others. This is because some substances are more efficient than others at converting absorbed energy into emitted energy. Intensity will also depend on the concentration of the fluorescing material - if there just isn't very much of it, it can't be very bright.

It is worth noting here that fluorescence is related to but quite distinct from bioluminescence. In both processes the emission of light comes from electrons that have been stimulated to an unstable excited state. The difference is in how electrons get the energy to reach the excited state. In fluorescence they do it by absorbing photons of incident light. In bioluminescence the energy comes from reactions of chemicals present in the organism. Thus bioluminescent organisms emit their own light, while those that are fluorescent will only glow when there is an external light source of the right wavelength [9].

\section{Experimental work:}

The experimental aquarium setup illustrated in fig.5 which matches the extinction factor and turbidity of the sea water having a depth of $50 \mathrm{~m}$. The operating system simulates the airborne laser illumination of sea surface and the camouflaged submerged targets as shown in fig.6.

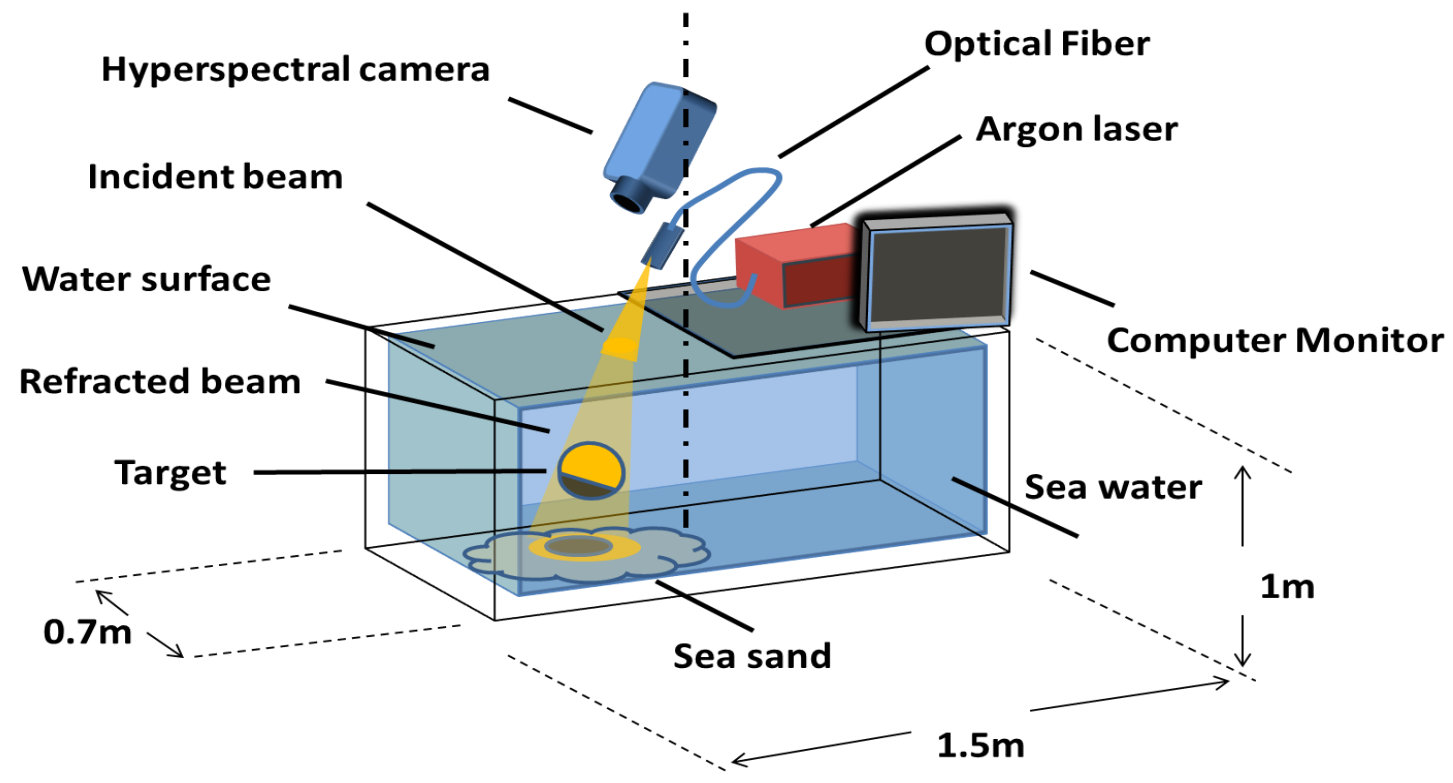

Fig.5 Experimental setup diagram 


\section{Military Technical College \\ Kobry Elkobbah, \\ Cairo, Egypt \\ April 3-5,2018}

9th International Conference on Mathematics and

Engineering Physics (ICMEP-9)

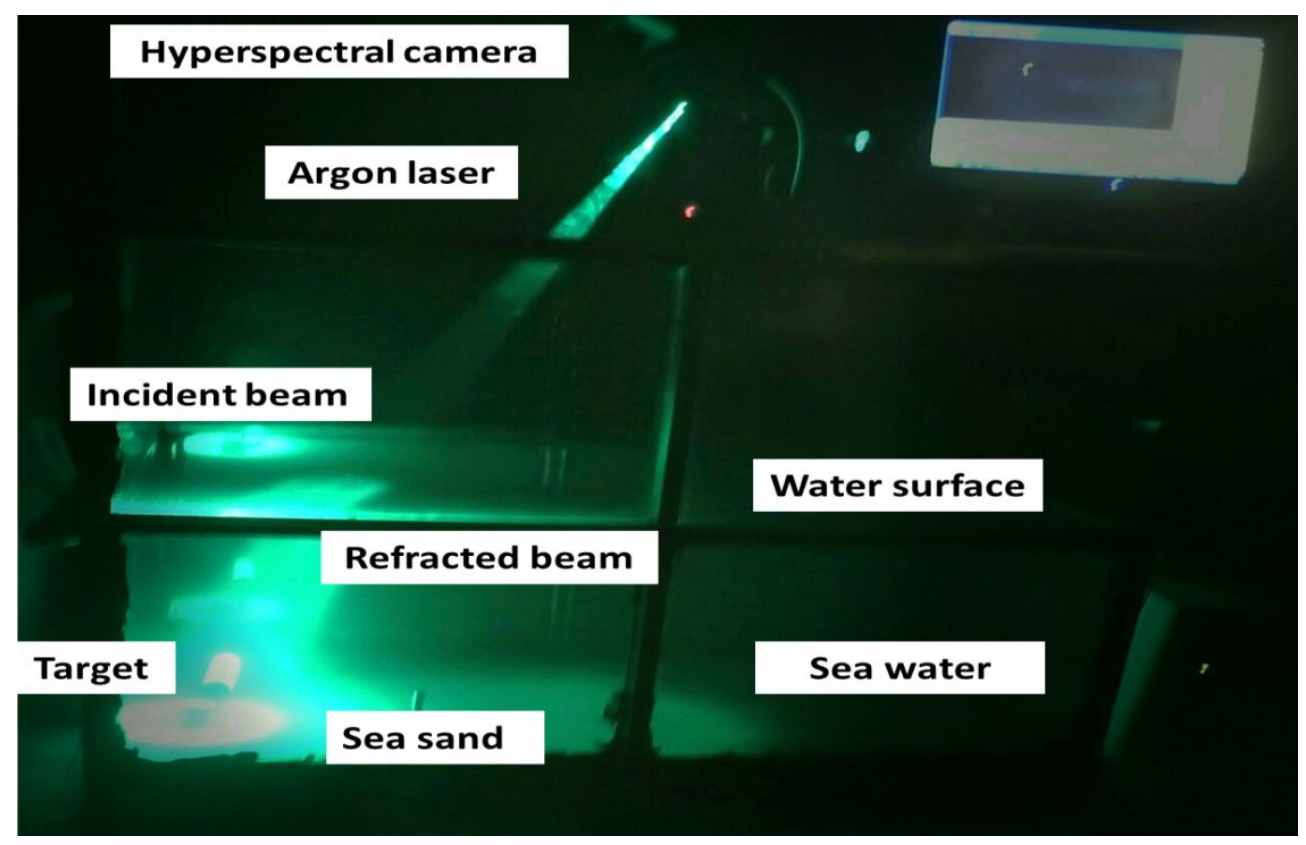

Fig. 6 underwater target illumination and detection using the designed experimental setup

The illustrated operating system is used in hyperspectral photography getting 27 image cube formed as a combination of three types of camouflaged dummy targets (square - cylinder - sphere)) in three different backgrounds (sea sand - coastal mud - clay) illuminated by the Argon laser [with multiple output wavelengths $(457 \mathrm{~nm}-488 \mathrm{~nm}-514 \mathrm{~nm})$ ] through the optical fiber terminal that took three angles of inclination $\left(90^{\circ}-75^{\circ}-60^{\circ}\right)$. These hyperspectral image cubes were studied to distinguish different target detectivity cases and get the best correlation.

Fig.7 represents the hyperspectral photography formed for the case of the sand background where figs.7 $(\mathrm{a}, \mathrm{b}, \mathrm{c})$ shows the images in the case of normal incidence for the used three targets, figs. $7(\mathrm{~d}, \mathrm{e}, \mathrm{f})$ shows the images in the case of $75^{\circ}$ incidence, and figs. $7(\mathrm{~g}, \mathrm{~h}, \mathrm{i})$ shows the images in the case of $60^{\circ}$ incidence. 
Military Technical College

Kobry Elkobbah,

Cairo, Egypt

April 3-5,2018

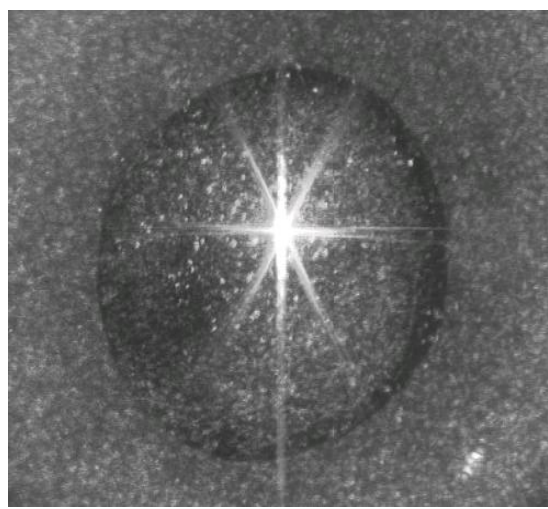

(a)

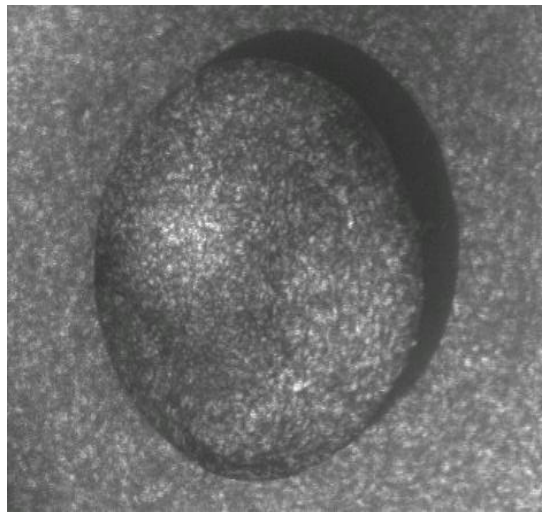

(d)

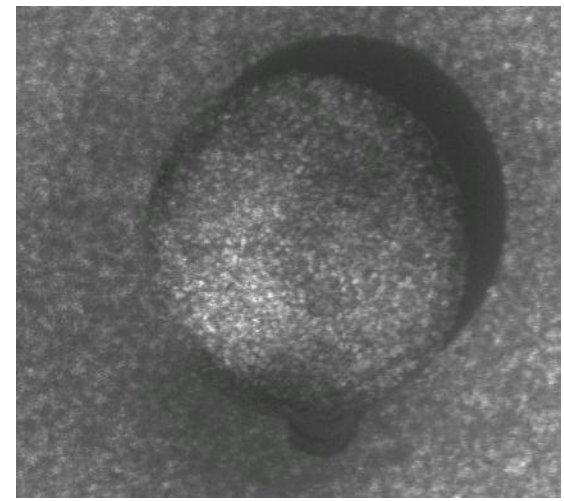

(g)

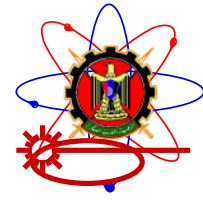

9th International Conference on Mathematics and

Engineering Physics (ICMEP-9)

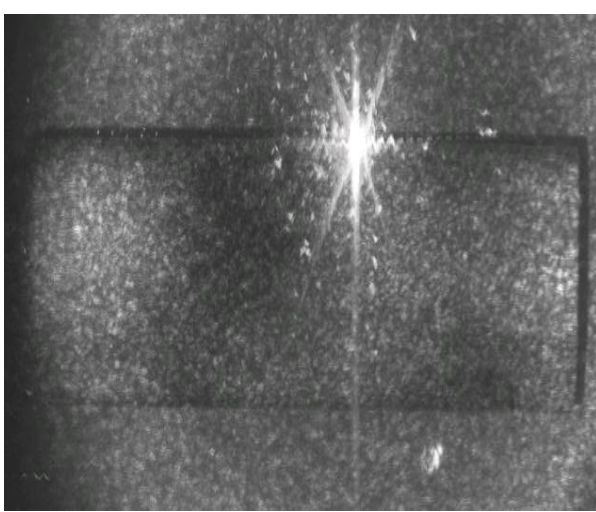

(b)

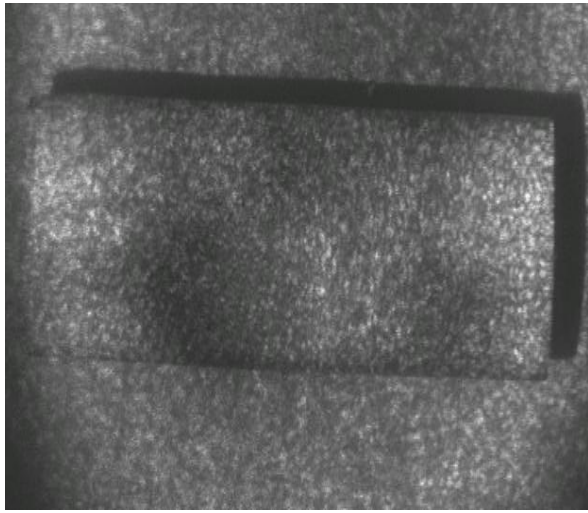

(e)

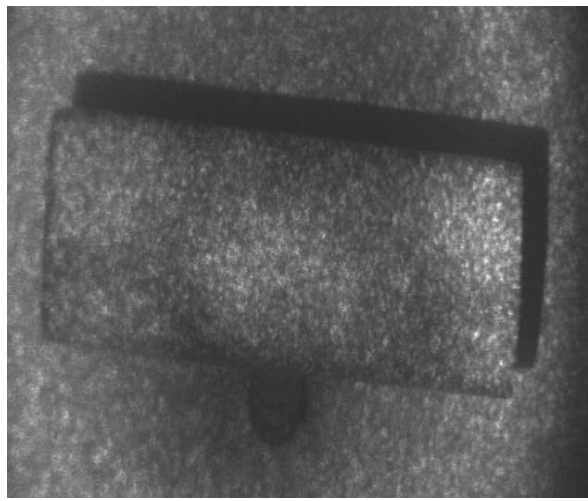

(h) (c)

(f)
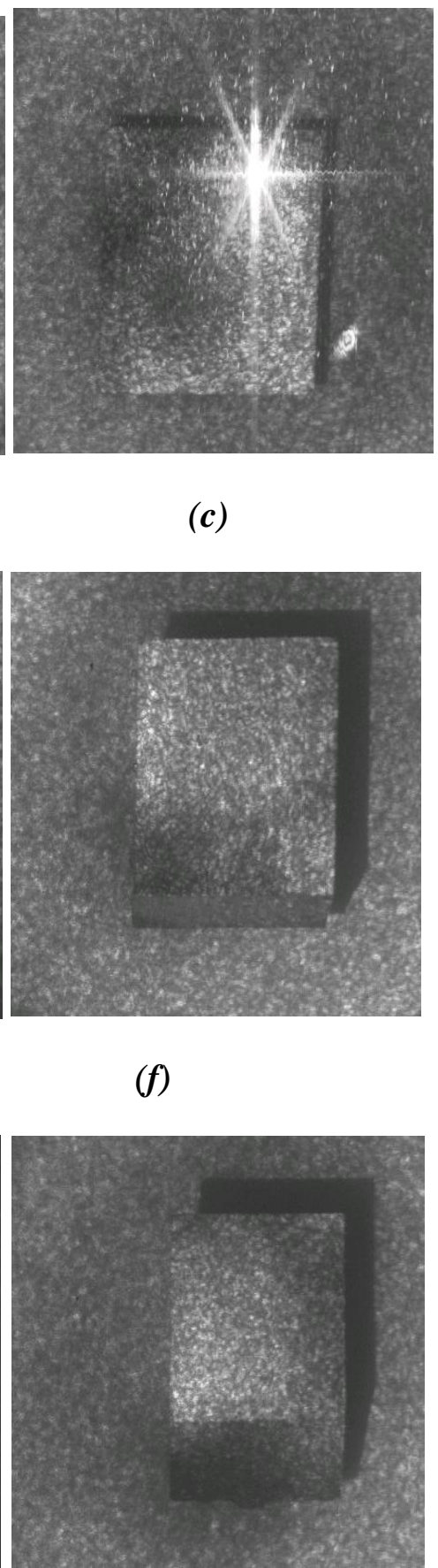

(i)

Fig. 7 hyperspectral image of the camouflaged underwater target for sand background at different detection angles 
Military Technical College

Kobry Elkobbah,

Cairo, Egypt

April 3-5,2018

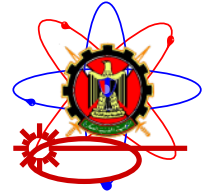

9th International Conference on Mathematics and

Engineering Physics (ICMEP-9)

The two cases of deep sea water and coastal water ware simulated in our experimental test aquarium and this study leads to, in the case of deep water the detectivity of the targets is more better than that for coastal water because the experimental prepared phytoplankton causes fluorescence and decreases the imaging contrast and the detectivity of the targets. Fig.8 illustrates the emission and excitation for the argon laser wavelengths and it is shown in fig. $8 \mathrm{~b}$ the broadening occurred due to fluorescence which reduces the target detectivity.

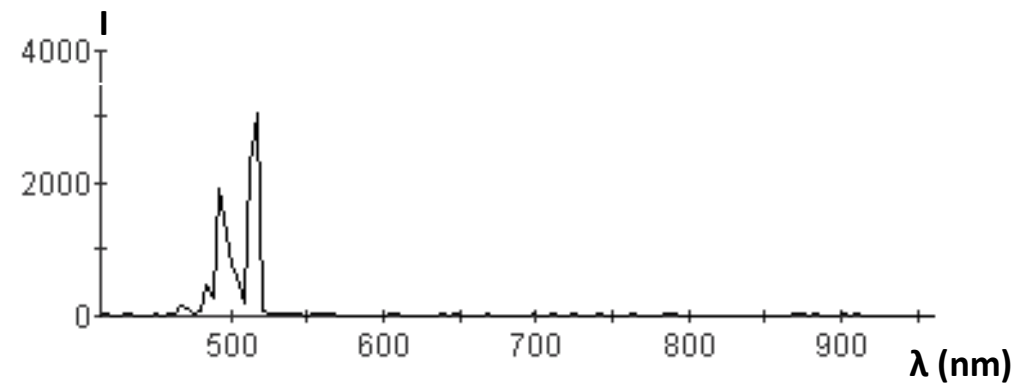

(a)

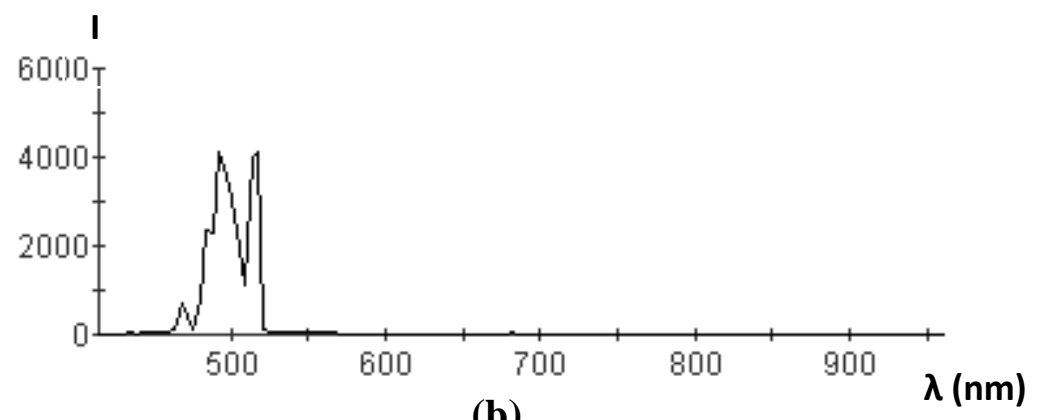

(b)

Fig.8 Emission (a) and excitation (b) spectra for two of the common fluorescent pigments found in the sea water for argon laser

\section{Conclusion}

Hyperspectral imaging increases the detectivity of underwater camouflaged targets at different levels of optical extinction and turbidity. Tests revealed that the best imaging angle is $90^{\circ}$ and decreases for $75^{\circ}$ and $60^{\circ}$, the best background for target detectivity is the sand then clay and the worst is mud, Plankton causes fluorescence in the coastal water and decreases the imaging contrast and the detectivity of the targets but the detectivity increases in the deep sea water, the best camouflaged target shape is the squared then cylinder and the worst is the sphere, and the best wavelength for the case of Argon laser source at 512nm and 491nm 
Military Technical College

Kobry Elkobbah,

Cairo, Egypt

April 3-5,2018

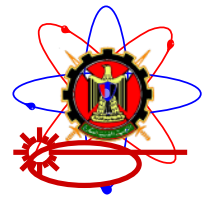

9th International Conference

on Mathematics and

Engineering Physics (ICMEP-9)

\section{References:}

[1] J. R. Apel, "Principles of Ocean Physic", International Geophysics Series, Vol. 38, 509-584, Academic Press, (1987)

[2] H. Arst, "Optical Properties and Remote Sensing of Multicomponental Water Bodies", Praxis Publishing, Chichester, UK, pg 8-28, (2003)

[3] Chen YangWei, "Field measurement of laser attenuation in natural water", Marine Technology, China, 41-48 vol. 1, 2, 2000

[4] Volent, Z., Johnsen, G., \& Sigernes, F. (2009). Microscopic hyperspectral imaging used as biooptical taxonomic tool for micro- and macroalgae. Applied Optics, 48, 4170-4176.

[5] Sakshaug, E., Johnsen, G., \& Volent, Z. (2009). Light. In E. Sakshaug, G. Johnsen \& K. Kovacs (Eds.), Ecosystem Barents Sea (pp. 117-138). Trondheim, Norway: Tapir Academic Press.

[6] Mobley, C. (1994), Light and Water: Radiative Transfer in Natural Waters, Harcourt Publishers Ltd.

[7] Moline, M. A., M. J. Oliver, C. D. Mobley, L. Sundman, T. Bensky, T. Bergmann, W. P. Bissett, J. Case, E. H. Raymond, O. M. E. Schofield, "Bioluminescence in a complex coastal environment: 1. Temporal dynamics of nighttime water-leaving radiance", J Geophys. Res, vol. 112, no. C11016, 2007.

[8] C. M. Herren, S. H. D. Haddock, C. Johnson, C. Orrico, M. A. Moline, J. F. Case, "A multiplatform bathyphotometer for fine-scale coastal bioluminescence research", Limnol. Oceanogr. Methods, vol. 3, pp. 247-262, 2005.

[9] I. Shulman, S. H. D. Haddock, D. J. McGillicuddy, J. D. Paduan, W. P. Bisset, "Numerical modeling of bioluminescence distributions in the coastal ocean", Journal of Atmospheric and Oceanic Technology, vol. 20, pp. 1060-1068, 2003. 